\title{
Ever-expanding clinical implications of QT interval prolongation
}
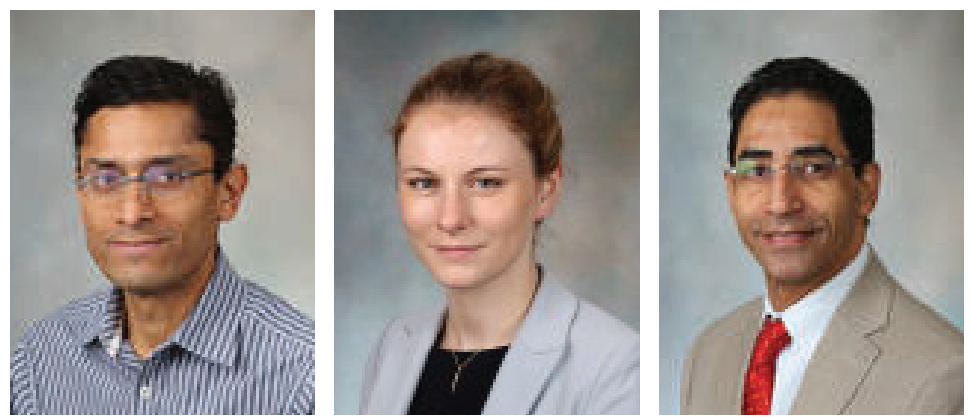

Harish Ramakrishna ${ }^{* 1}$, Meabh O'Hare $^{2}$ \& Farouk Mookadam²

Polymorphic ventricular tachycardia characterized by an electrocardiographic pattern of continuously changing morphology of QRS complexes that seem to twist around the imaginary baseline [1]. A Torsade de pointes (TdP) is a distinctive ventricular arrhythmia first described by Dessertenne in 1966 [2] and named for its electrographic resemblance to a spinning ballerina. In the modern era, it is increasingly relevant as a preventable complication in the perioperative period in susceptible patients, where underling genetic predisposition, electrolyte abnormalities and certain medications result in QT interval prolongation that can culminate in this potentially lethal arrhythmia.

The past decade has witnessed significant advances in our understanding of the potentially lethal effects of QT interval prolongation in both low [3-5] and high cardiovascular risk patients [6,7]. Advances into the genetic basis of QT interval prolongation in its hereditary form continues steadily following the original description by Jervell and Lange-Nielsen in 1957 of an autosomal recessive syndrome characterized by prolonged QT interval and congenital deafness [8]. In the years that have ensued, 16 genes have been identified as responsible or associated with congenital long QT syndrome (LQTS). Three main genes - KCNQ1 (LQT1), KCNH2 (LQT2) and SCN5A (LQT3) account for almost $75 \%$ of LQTS cases $[9,10]$.

The perioperative period, with its associated physiological stress, can unmask latent LQTS in susceptible patients. For the perioperative clinician, the worst-case scenario is the patient with latent or unrecognized LQTS developing TdP. A host of precipitating factors are frequently encountered in surgical patients, including druginduced bradycardia, electrolyte abnormalities (hypokalemia, hypomagnesemia and hypocalcemia), baseline QT prolongation, the use of QT interval prolonging medications and frequent changes in adrenergic tone in conjunction with drug synergism from inhaled and intravenous anesthetics. These factors, in the appropriately 'primed' or vulnerable patient

\section{KEYWORDS}

- congenital • QTc prolongation

- QT prolonging drugs $\bullet$ Torsade de pointes

\section{“The unwitting clinician therefore may be in harm's way as much as causing harm."}


“...prolongation of the QT interval is a simple electrographic finding of great significance in the perioperative period...” can have lethal consequences if unrecognized. Iatrogenic LQTS provoked by the use of certain QT-prolonging agents is a significant problem worldwide, and its incidence and impact is likely underestimated [11,12]. In one study, patients were actively screened for LQTS/TdP and associated drug exposures were identified. Using WHO criteria to establish causality, 60\% of identified cases of LQTS/TdP were found to be drug induced. A crude annual incidence of drug-induced LQTS/TdP was calculated at 3.2-3.7 per million person years, significantly higher than the rate of 0.26 per million person years that had been spontaneously reported. Adding to the conundrum is the number of QT-prolonging drugs previously not being listed on the official list of standard offending agents, with 19 unlisted drugs causing 27 reactions [13]. This study raises the important issue of the urgent need for accurate and prompt reporting of drugs that may predispose to sudden cardiac death (SCD) in susceptible patients.

The unwitting clinician therefore may be in harm's way as much as causing harm. As a result of unexpected QT prolongation, antibiotics such as grepafloxacin, antipsychotics such as sertindole and antihistamines such as terfenadine or astemizole have been removed from the market [14].

Resources such as 'CredibleMeds' (an updated database of QTc prolonging medications) are now being incorporated into the e-prescribing systems by institutions to alert clinicians of potentially dangerous combinations [15]. However, physician vigilance remains of paramount importance, as one study demonstrated that in patients prescribed two concurrent QT-prolonging medications, baseline ECG was only obtained in a third, despite the presence of e-prescribing alerts [16].

Also of interest is new data that correlates baseline QTc prolongation with a greater incidence of cardiovascular events in healthy patients. In a recent study by Beinart et al. [17], a dose-response relationship was demonstrated between prolongation of the QT interval and an associated increased incidence of cardiovascular events. This study recruited more than 6000 patients (mean age: $61.7 \pm 10.7$ years) with no clinical evidence of cardiovascular disease at baseline and followed them for 8 years $( \pm 1.7$ years $)$. Patients on any antiarrhythmic or QT-prolonging medications were excluded. Using a Cox proportional hazards model adjusting for age, ethnicity and vascular risk factors, each $10 \mathrm{~ms}$ increase in the baseline QTc was associated with a significant increase $(\mathrm{p}<$ 0.001 ) in the risk of heart failure (hazard ratio [HR]: 1.27), cardiovascular disease (HR: 1.15) and stroke (HR: 1.20) on follow-up.

Similarly, the REGARDS trial demonstrated an almost threefold increased risk of stroke in patients with baseline QT interval prolongation after adjustment was made for traditional stroke risk factors (HR: 2.88; 95\% CI: 2.12-3.92; $\mathrm{p}<0.0001)$ [18]. Prolonged QTc was defined as $>450 \mathrm{~ms}$ in males and $>460 \mathrm{~ms}$ in females. These findings may have particular relevance in the perioperative period as perioperative stroke is associated with an eightfold increased risk of mortality [19].

The mechanism underlying this association between QT prolongation and increased incidence of cardiovascular events may be related to elevated catecholamine levels. Increased sympathetic drive is known to prolong the QT interval even in healthy subjects $[20,21]$ and is also associated with acceleration of atherosclerosis by multiple mechanisms including the direct atherogenic effect of catecholamines; induction of dyslipidemia; platelet activation and vascular remodeling [22].

In this fashion, mild QT interval prolongation in otherwise clinically healthy individuals may serve as an early warning of underlying cardiovascular risk, in other words, a 'canary in the coalmine' [23]. The relevance of this data to clinical practice may lie in the identification of modestly prolonged QT intervals in healthy individuals prompting a more thorough evaluation for vascular risk factors. The use of $\beta$-blockers in this population is also a potential area of interest [23].

With the proliferation of new data, it becomes increasingly apparent that significant questions remain unanswered. The widespread use of antipsychotic drugs, antihistamines and other known LQTS/TdP triggers in surgical patients presenting for cardiac and noncardiac surgery, meticulous preoperative assessment, a detailed knowledge of the medication history, avoidance of all drugs that are linked to drug-induced QTc prolongation/TdP and a sound anesthetic plan with postoperative monitoring and long-term follow-up are essential for optimal cardiovascular outcomes in all patients.

In short, prolongation of the QT interval is a simple electrographic finding of great significance in the perioperative period and should 
alert the vigilant clinician to both the increased risk of underlying cardiovascular risk as well as the potential for iatrogenic harm in this setting.

\section{Financial \& competing interests disclosure}

The authors have no relevant affiliations or financial

involvement with any organization or entity with a financial interest in or financial conflict with the subject matter or materials discussed in the manuscript. This includes employment, consultancies, honoraria, stock ownership or options, expert testimony, grants or patents received or pending, or royalties.

No writing assistance was utilized in the production of this manuscript.

\section{References}

1 Slama R, Motte G, Coumel P, Dessertenne F. [The syndrome, "QT lengthening and syncope due to torsion of the points"]. Laval. Med. 42, 353-366 (1971).

2 Dessertenne F. [Ventricular tachycardia with 2 variable opposing foci]. Arch. Mal. Coeur Vaiss. 59, 263-272 (1966).

3 Dekker JM, Crow RS, Hannan PJ, Schouten EG, Folsom AR. Heart rate-corrected QT interval prolongation predicts risk of coronary heart disease in black and white middle-aged men and women: the ARIC study. J. Am. Coll. Cardiol. 43, 565-571 (2004).

4 Noseworthy PA, Peloso GM, Hwang SJ et al. QT interval and long-term mortality risk in the Framingham Heart Study. Ann. Noninvasive Electrocardiol. 17, 340-348 (2012).

5 Schouten EG, Dekker JM, Meppelink P, Kok FJ, Vandenbroucke JP, Pool J. QT interval prolongation predicts cardiovascular mortality in an apparently healthy population. Circulation 84, 1516-1523 (1991).

6 Peters RW, Byington RP, Barker A, Yusuf S. Prognostic value of prolonged ventricular repolarization following myocardial infarction: the BHAT experience. The BHAT Study Group. J. Clin. Epidemiol. 43, 167-172 (1990).

7 Williams ES, Thomas KL, Broderick S et al. Race and gender variation in the QT interval and its association with mortality in patients with coronary artery disease: results from the Duke Databank for Cardiovascular Disease
(DDCD). Am. Heart J. 164, 434-441 (2012).

8 Jervell A, Lange-Nielsen F. Congenital deaf-mutism, functional heart disease with prolongation of the Q-T interval and sudden death. Am. Heart J. 54, 59-68 (1957).

9 Schwartz PJ, Crotti L, Insolia R. Long-QT syndrome: from genetics to management. Circ. Arrhythm. Electrophysiol. 5, 868-877 (2012).

10 Wang Q, Shen J, Splawski I et al. SCN5A mutations associated with an inherited cardiac arrhythmia, long QT syndrome. Cell 80, 805-811 (1995).

11 Rao P, Kowey PR. Drug-induced long-QT syndrome and torsade de pointes: an underrated problem? Europace 16, 4-5 (2014).

12 Sarganas G, Garbe E, Klimpel A, Hering RC, Bronder E, Haverkamp W. Epidemiology of symptomatic drug-induced long QT syndrome and Torsade de Pointes in Germany. Europace 16, 101-108 (2014).

13 AZCERT I. Arizona Center for Education and Research on Therapeutics. www.crediblemeds.org

14 Roden DM. Drug-induced prolongation of the QT interval. N. Engl. J. Med. 350, 1013-1022 (2004).

15 Haugaa KH, Bos JM, Tarrell RF, Morlan BW, Caraballo PJ, Ackerman MJ. Institutionwide QT alert system identifies patients with a high risk of mortality. Mayo Clin. Proc. 88, 315-325 (2013).

16 van der Sijs H, Kowlesar R, Klootwijk AP, Nelwan SP, Vulto AG, van Gelder T.
Clinically relevant QTc prolongation due to overridden drug-drug interaction alerts: a retrospective cohort study. Br. J. Clin. Pharmacol. 67, 347-354 (2009).

17 Beinart R, Zhang Y, Lima JA et al. The QT interval is associated with incident cardiovascular events: the MESA study. J. Am. Coll. Cardiol. 64, 2111-2119 (2014).

18 Soliman EZ, Howard G, Cushman M et al. Prolongation of QTc and risk of stroke: the REGARDS (REasons for Geographic and Racial Differences in Stroke) study. J. Am. Coll. Cardiol. 59, 1460-1467 (2012).

19 Mashour GA, Shanks AM, Kheterpal S. Perioperative stroke and associated mortality after noncardiac, nonneurologic surgery. Anesthesiology 114, 1289-1296 (2011).

20 Baumert M, Lambert GW, Dawood T et al. QT interval variability and cardiac norepinephrine spillover in patients with depression and panic disorder. Am. J. Physiol. Heart Circ. Physiol. 295, H962-H968 (2008).

21 Vyas H, Hejlik J, Ackerman MJ. Epinephrine QT stress testing in the evaluation of congenital long-QT syndrome: diagnostic accuracy of the paradoxical QT response. Circulation 113, 1385-1392 (2006).

22 Pauletto P, Scannapieco G, Pessina AC. Sympathetic drive and vascular damage in hypertension and atherosclerosis. Hypertension 17, III75-81 (1991).

23 Moss AJ. Is modest QT interval prolongation in normal adults like the canary in the coal mine? J. Am. Coll. Cardiol. 64, 2120-2121 (2014). 